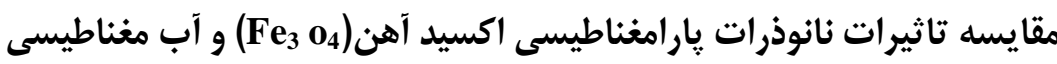 بر رشد قارج فوزاريوم اتزيسبوروم اكيديد الهن
}

\author{
يرديس باباشاهى'، نوشين نقش '، محبوبه مدنى'
}

1) كروه ميكروبيولوثى، ولحد فلاورجان، دانشكاه آزاد اسلامى، (صفهان، ايران

N) كروه زيست شناسى، ولحد فلاورجان، دانشكاه آزاد اسلامى، (صفهان، ايران

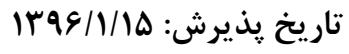

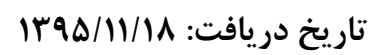

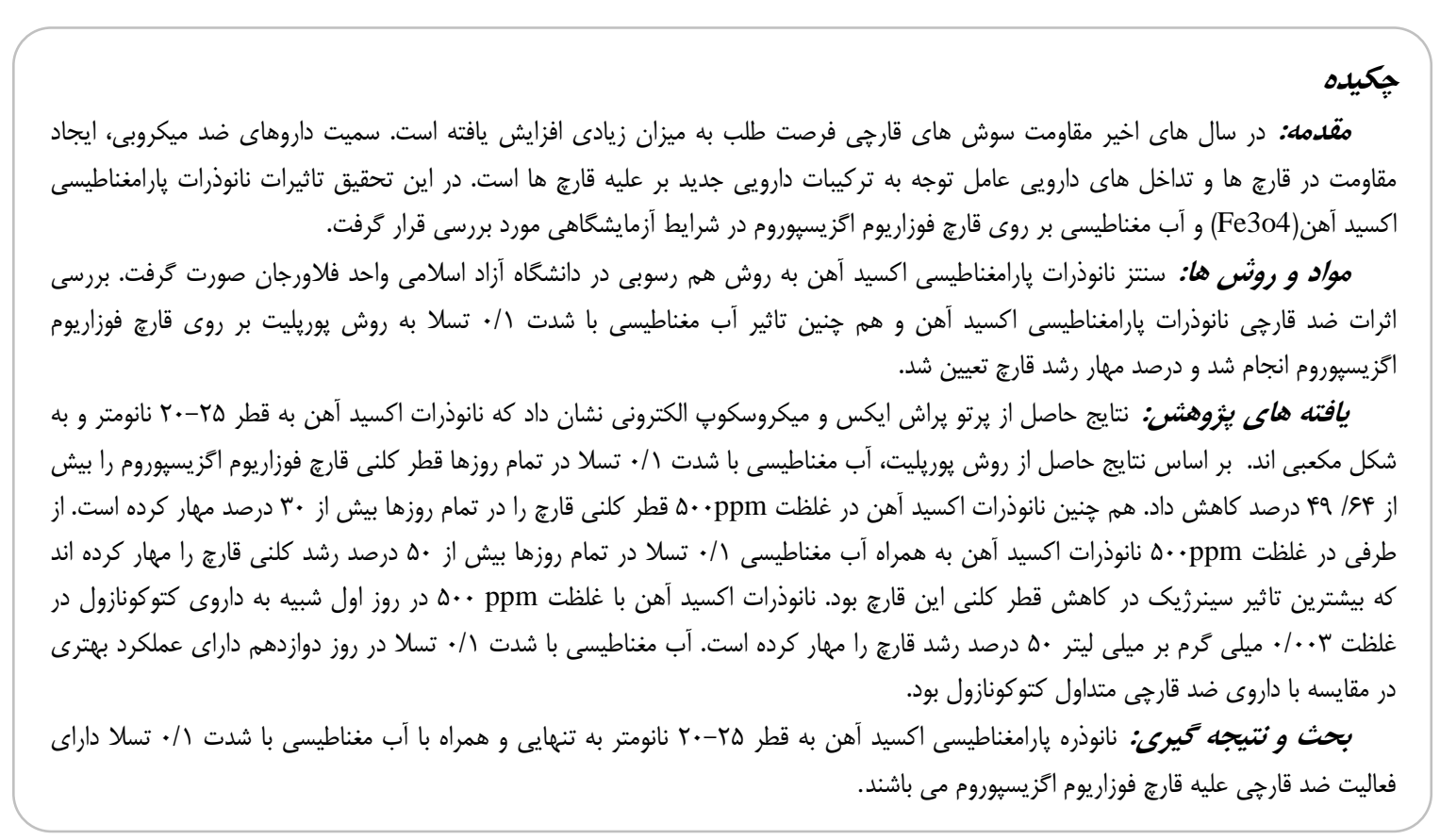

وازه هاى كليدى: نانوذرات يارامغناطيسى اكسيد آهن، آب مغناطيسى، قارج فوزاريوم اززيسيوروم، اثر ضد قارجى

Email:n_naghsh@yahoo.com

* *ويسنده مسئول: گروه زيست شناسى، واحد فلاورجان، دانشخاه آزاد اسلامى، اصفهان، ايران

Copyright (C) 2018 Journal of Ilam University of Medical Science. This is an open-access article distributed under the terms of the Creative Commons Attribution international 4.0 International License (https://creativecommons.org/licenses/by-nc/4.0/) which permits copy and redistribute the material, in any medium or format, provided the original work is properly cited. 
قرار مى كيرند و ذرات بسيار كوجى آهن كه ويزّى

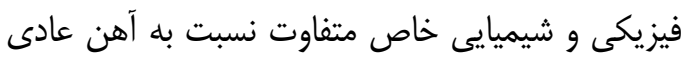

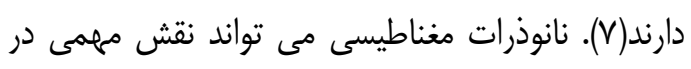

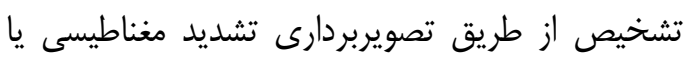

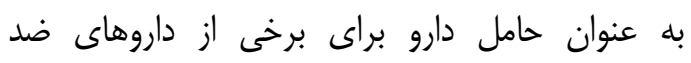

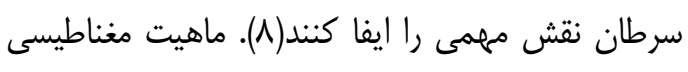

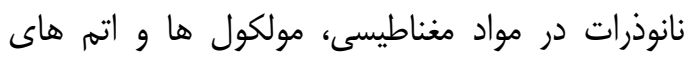
سازنده آن خاصيت مغناطيسى دارند به بيان ساده تر مادر مان

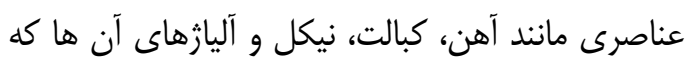
توسط آهن ربا جذب مى گردد، مواد مغناطيسى ناميده مى شود. قابليت مغناطيسى شدن نانوذرات اكسيد آهن

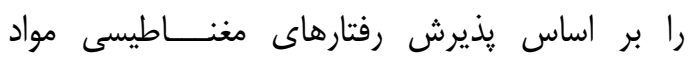
ابريارامغناطيس دسته بندى مى كنند(9). وقتى اندازه

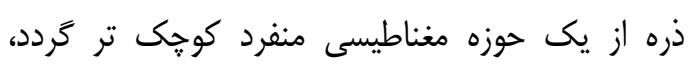

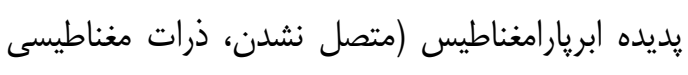

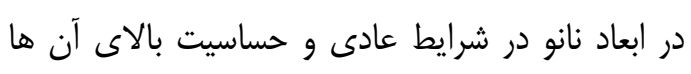

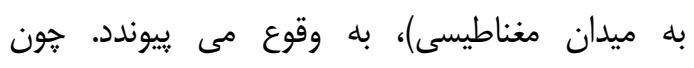
نانوذرات نياز به نيروى زيادى براى مغناطيسى شدن فئن

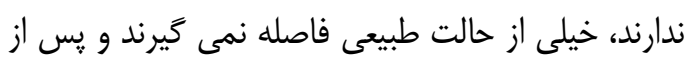

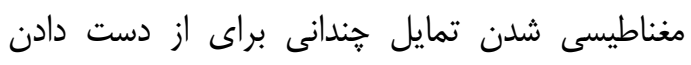

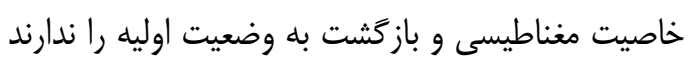

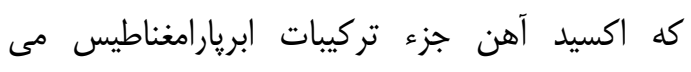

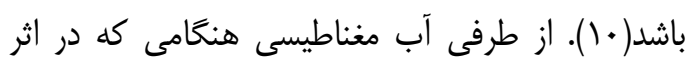

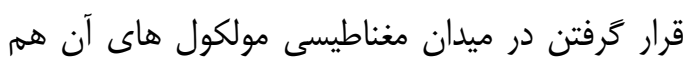

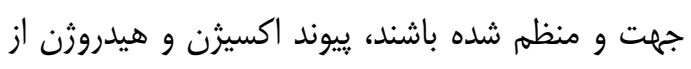

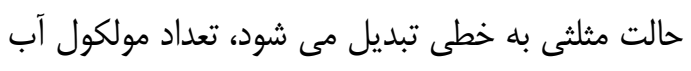

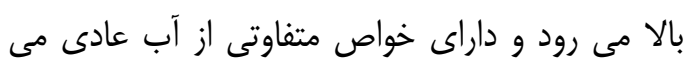

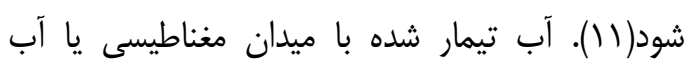

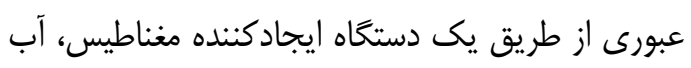

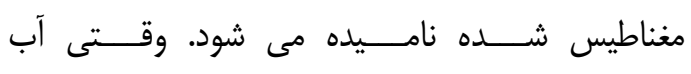

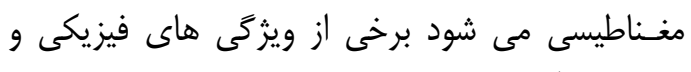

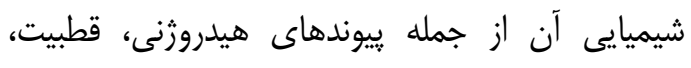

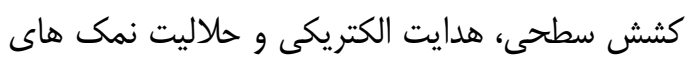

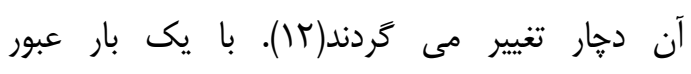

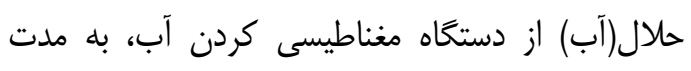
مان. أر r..

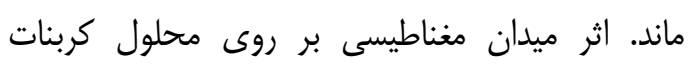

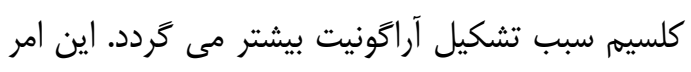

مقدمه فوزاريوزيس به گروهى از بيمارى ها اطلاق مى مى هاه شود كه توسط گَونه هاى مختلف فوزاريوم ايجاد مى بى شود. اين عوامل قارجى باعث ايجاد بيمارى در انسان

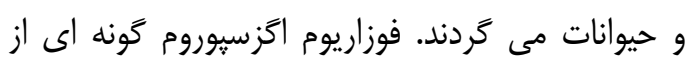

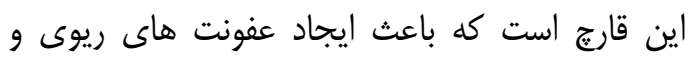

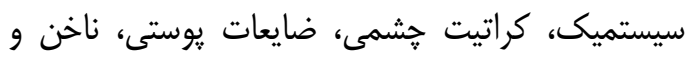

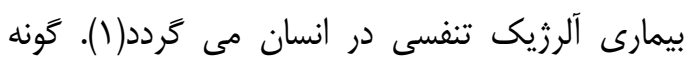

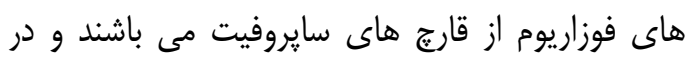

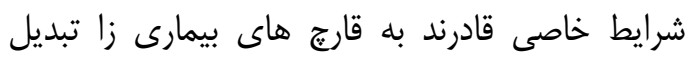

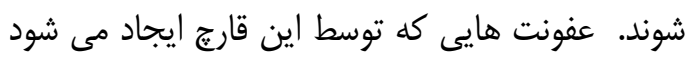
از جمله عفونت هايى هستند كه در افرادى كه سيسته إنها

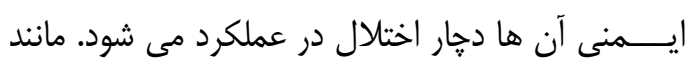
مبتلايان به سرطان كه تحت شيمى درمانى هستند،

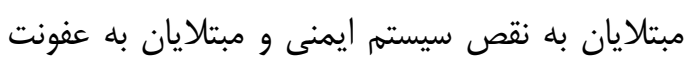

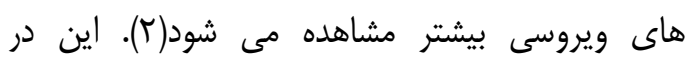

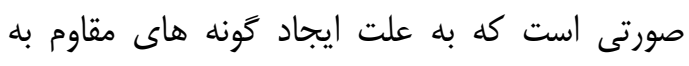

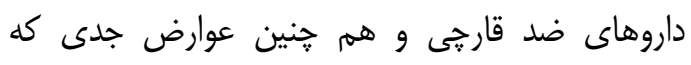

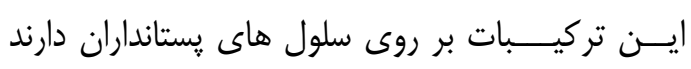

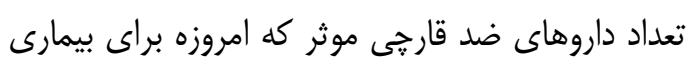

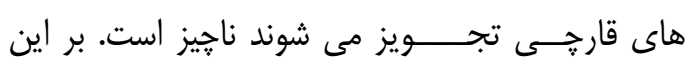

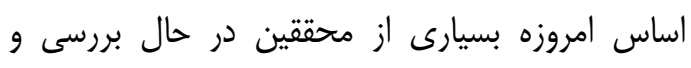

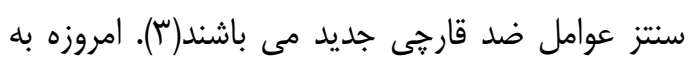

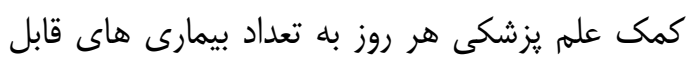

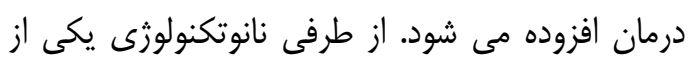

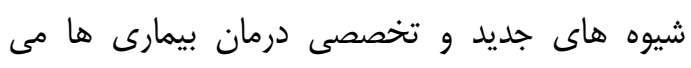

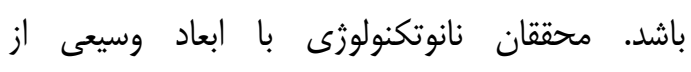

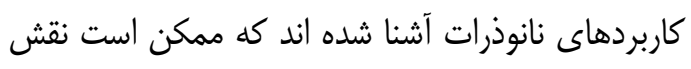
بسيار زيادى در يزشكى، ييشخيرى و درمان بيمارى ها

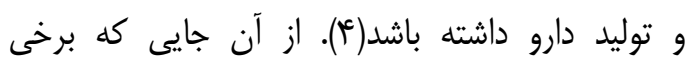

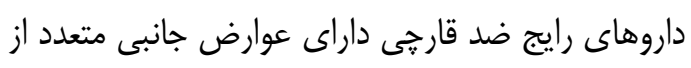
جمله سرطان و مسموميت هستند و هم جنين مقاومت إرواري دارويى در مصرف آن ها ايجاد مى شود(ه). در اين هم هنين

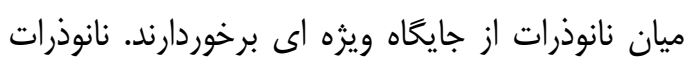

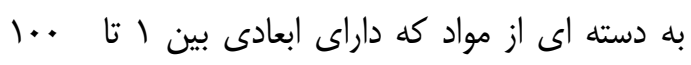

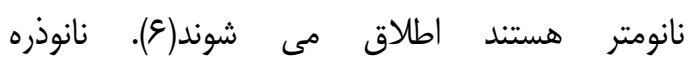
يارامغناطيسى اكسيدآهن به نانوذرات مكَنتيت به عنوان انوان نانوذرات اكسيد آهن در علم نانوتكنولوزى مورد استفاده 
يودر نمك در آب مقطر حل شود. در مرحله بعد از

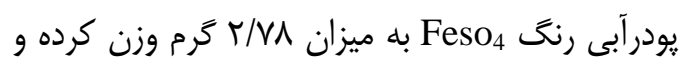

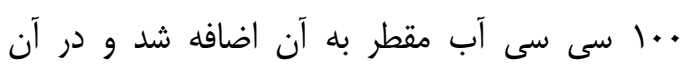

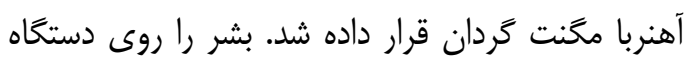

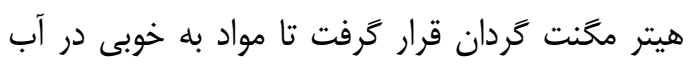
با هم مخلوط شوند و يودر مeso

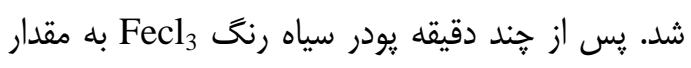

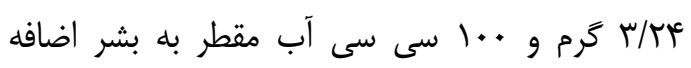

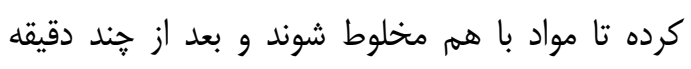

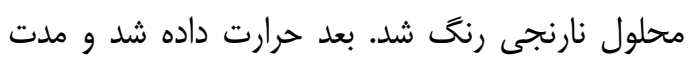

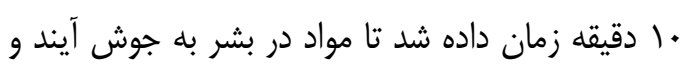

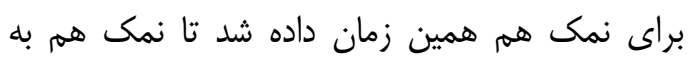

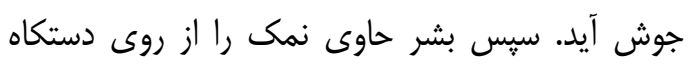

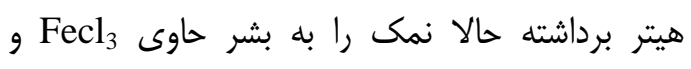

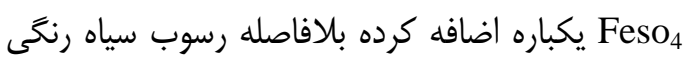

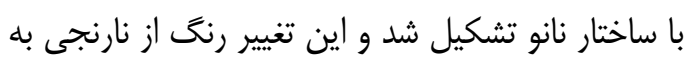

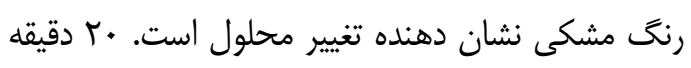

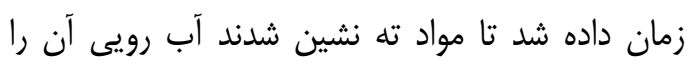
خالى كرده و كه در ه مرحله شست و شو شو انجام شد.

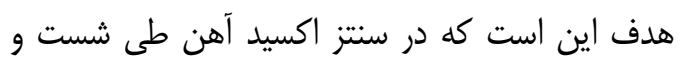

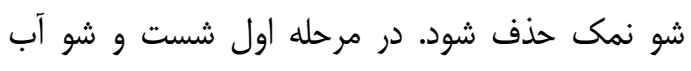

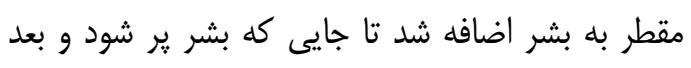
روى دستخاه هيتر مخنت گردان قرار داده شد. دستخاه

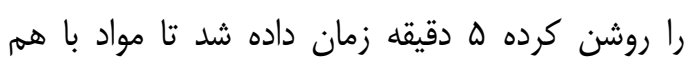

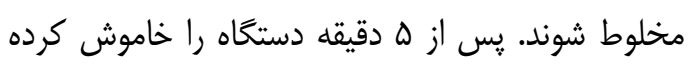

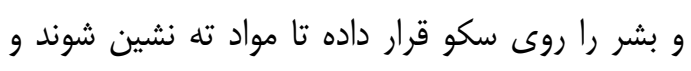

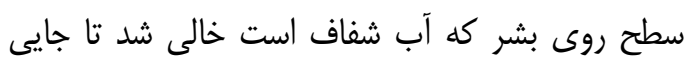

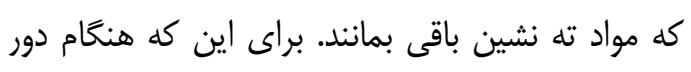

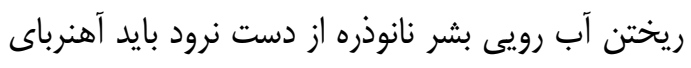

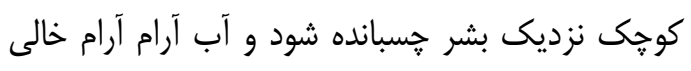

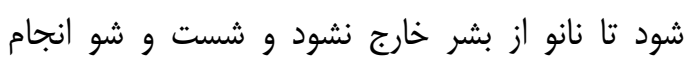

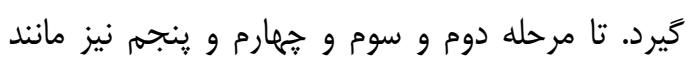

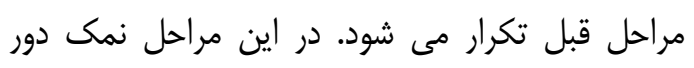

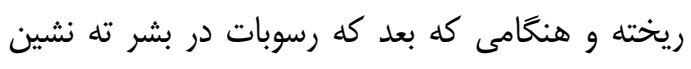

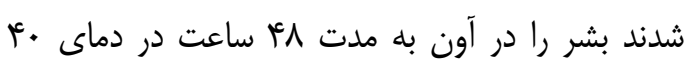

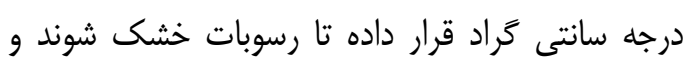

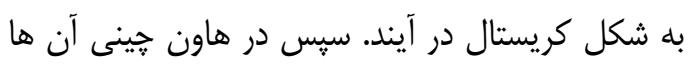
را يودر كرده تا در نهايت يودر نانوذره اكسيد آهن
براى انجام واكنش هاى شيميايى بسيار مهرم مى باشد

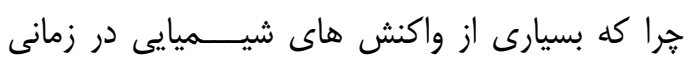

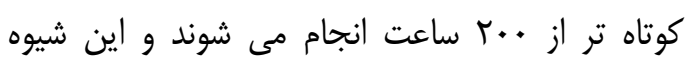

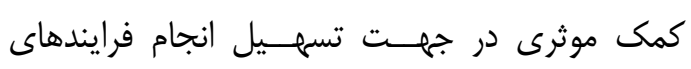

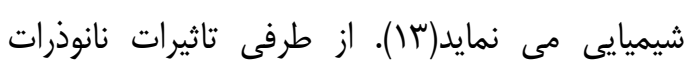

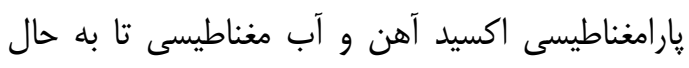

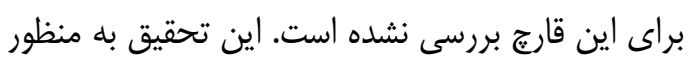

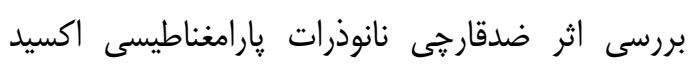

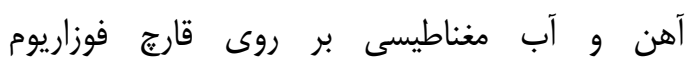
اگزيسيوروم در شرايط آزمايشآهى انجام شد.

مواد و روش ها سنوم دان قارج استاندارد مورد /ستناده: ميكرواركانسيم مورد

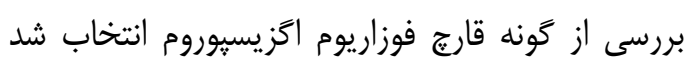

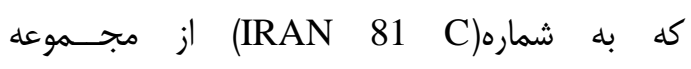

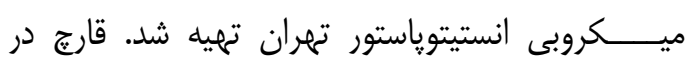

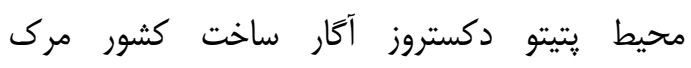
آلمان(PDA) كشت داده شد.

سنتز نانوذرات پإرامغناطيسى اكسيد آهن: نانوذرات

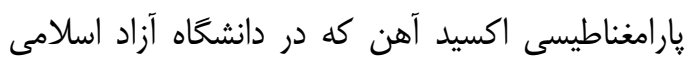

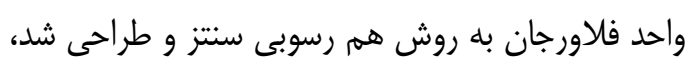

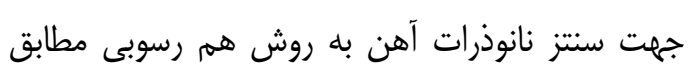
واكنش زير استفاده كرديده است :

$\mathrm{FeSO}_{4}+2 \mathrm{FeCl}_{3}+8 \mathrm{NaOH} \longrightarrow \mathrm{Fe}_{3} \mathrm{O}_{4}+$ $6 \mathrm{NaCl}+\mathrm{Na}_{2} \mathrm{So}_{4}+4 \mathrm{H}_{2} \mathrm{O}$

مقادير مناسب جرمى با توجه به واكنش بالا با در

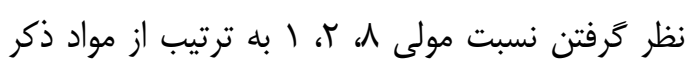

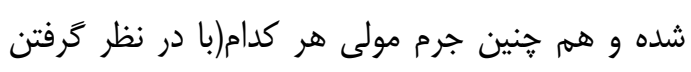
آب تبلور) در جدول شماره ا به دست جرم آمده است. ابتدا بشرها و آهنرباى كوجى و و آهنرباى مخَنت كردان كِيسولى با آب مقطر به خوبى شست و شو شو داده شدند تان

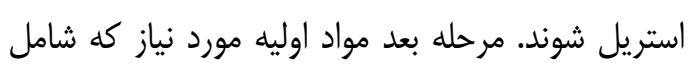

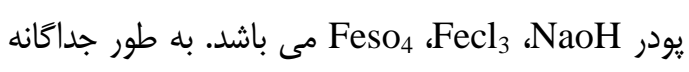

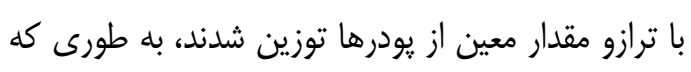

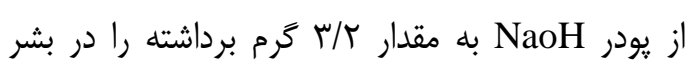

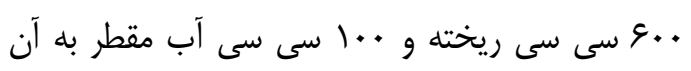
افزوده شد و بشر را روى دستخاه هيتر مخنت كردان

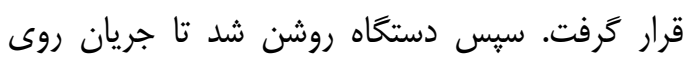

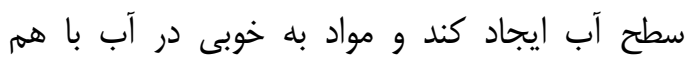

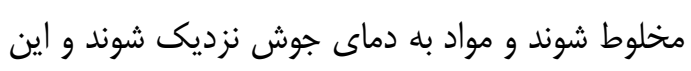


سرى شير را آرام باز كرده تا قطره قطره آب به داخل

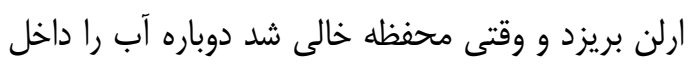

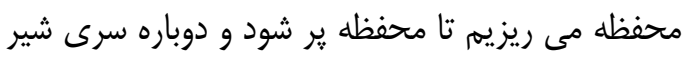

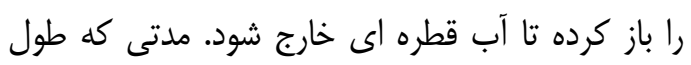

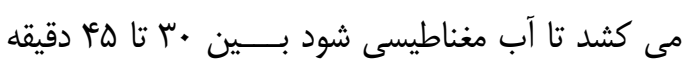

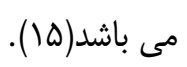

بررسى فعاليت ضدقارجى نانوذرات اكسيد آهن به آنه

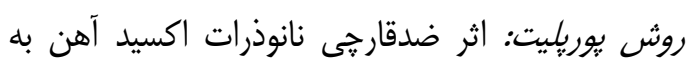

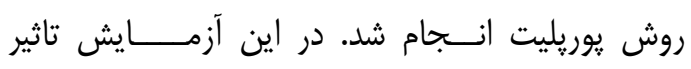
غلظت هاى مختلف نانوذرات اكسيد آهن كه شامل:

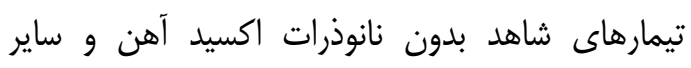

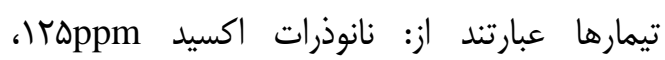
منظه منظور تعيين دوز موثر نانوذرات اكسيد آهن انجام شد.

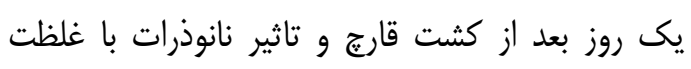

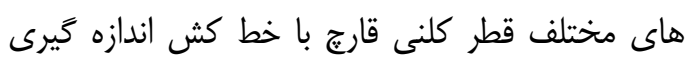

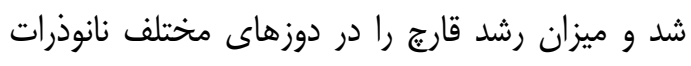

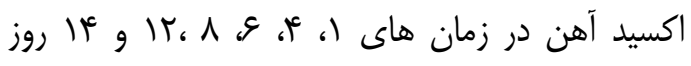

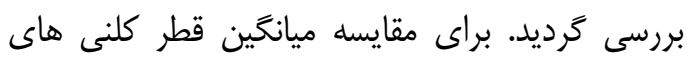

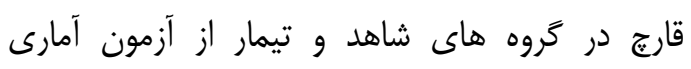
ANOVA

$$
\text { شد(1)، (1). }
$$

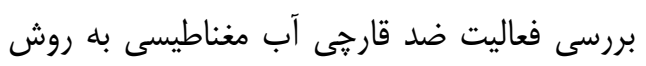
يوريليت به منظور سنجش اثر آب مغناطيسى مانند روش بالا عمل شد. اثر سينرزيك نانوذرات اكسيد آهن و آب مغناطيسى بالاعمل

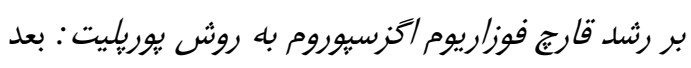

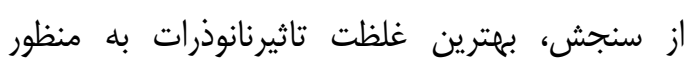

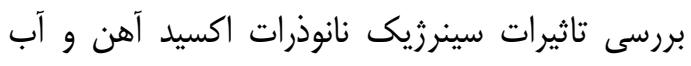

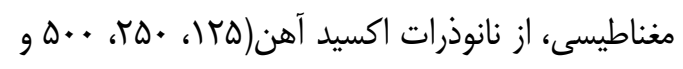
إنفا

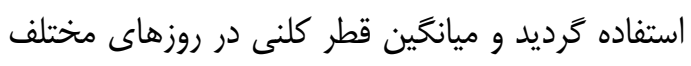

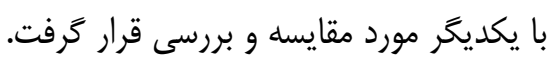
كنترل مثبت با داروى كتوكونازول: جهت مقايس متايسه

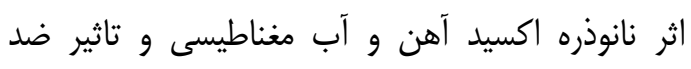

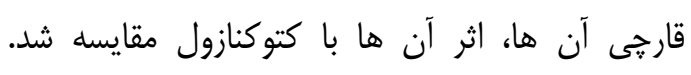

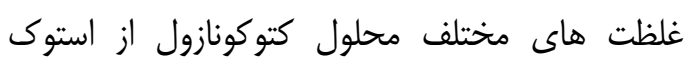
اصلى به روش سرى رقت تهيه شد. محلول
حاصل شود(شكل شماره (1). در طى تمام مراحل

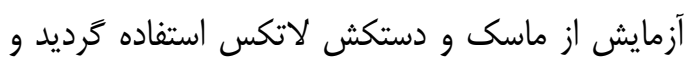

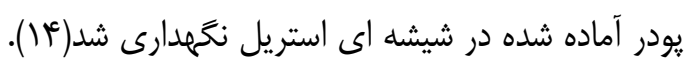

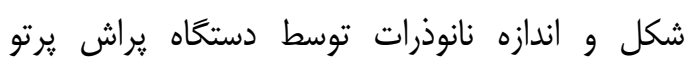
ايكس(مدل AW3040) و ميكروسكوٍ الكترونى(مدل

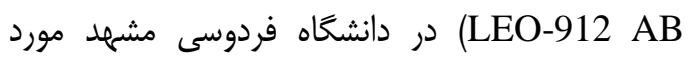
بررسى قرار گرفت (شكل شماره r و ؟r). بررسى خصوصيات مغناطيسى نانوذرات سنتز شده اكسيد آهن: ريز دانه هاى توريات

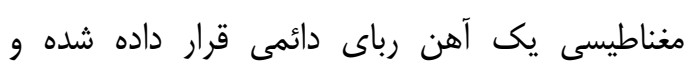

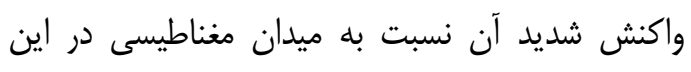

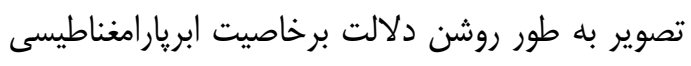
شدن اين نانوذرات دارد(شكل شماره عا).

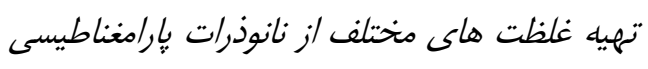

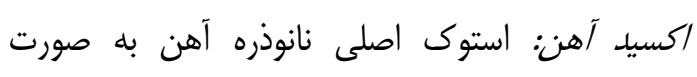

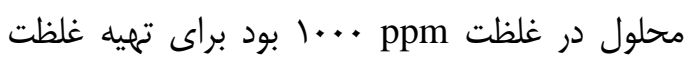
هاى مورد نياز از آب دو بار تقطير استريل استفاده شد.

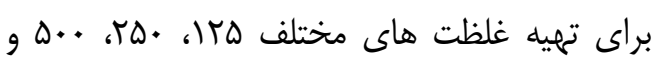
سازي سازى (Serial dilution) از استوى اصلى تمييه شد.

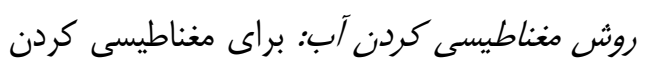

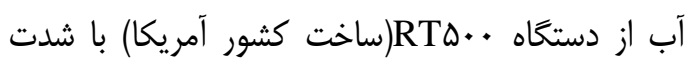

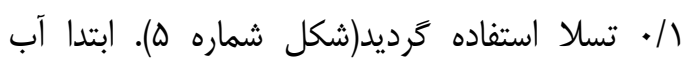
مقطر و و عدد ارلن را در اتوكلاو استريل مى كنيه.

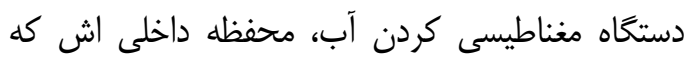

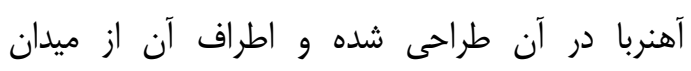

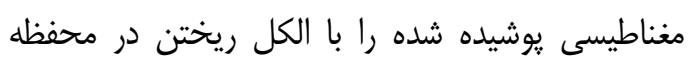
آن را استريل كرده و در نهايت با آب استريل جندين ريندين

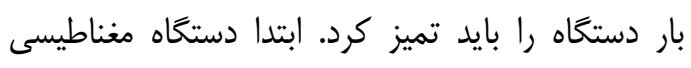

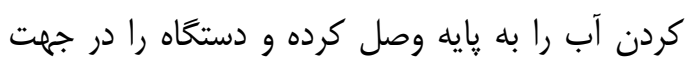
فلش نشان داده شده روى دستخاه به سمت بإيين قرار

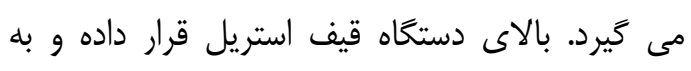
پايين دستخاه سرى شير وصل شد و زير شير ارلن قرار

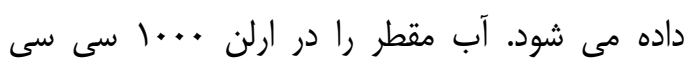

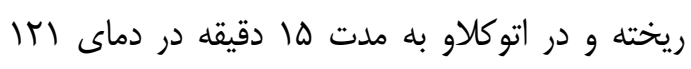

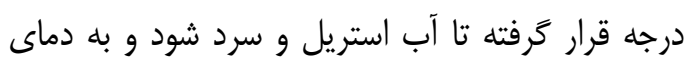
محيط برسد. بعد از آن آب را از بالاى دستخاه آن آن قدر

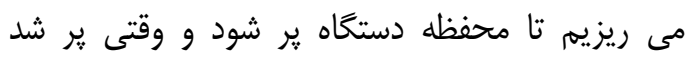




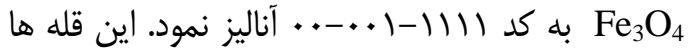
در واقع همان يرتوهايى هستند كه از قانون برات نمان

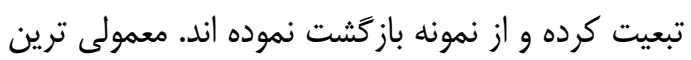

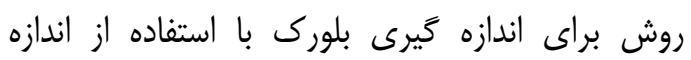

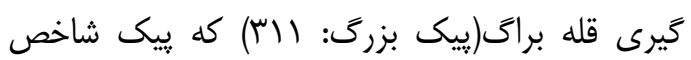

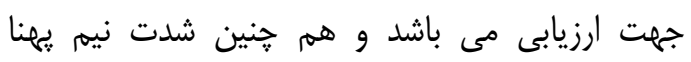
مربوط به الخوى XRD و با استفاده از رابطه دباى شرئ شرد تعيين مى گردد و داريه: كه در اين رابطه d اندازه بلورك(اندازه كريستال ذرات بر حسب نانومتر)، $\lambda$ طول

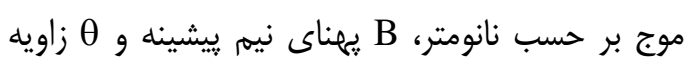

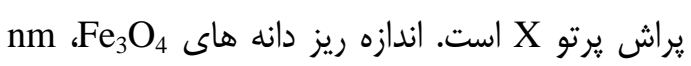

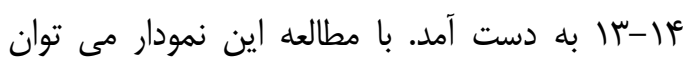
دريافت كه نمونه

$$
\begin{gathered}
\mathrm{d}=\frac{0.9 * \lambda}{\mathrm{B} * \cos \theta}=\frac{0.9 * 1.504}{0.6 * \frac{\pi}{180} * \cos \frac{35.6}{2}}=135.8 \mathrm{~A}= \\
13.5 \mathrm{~nm} \underset{\mathrm{nm}}{\mathrm{B}=\frac{36.07}{35.4}}=0.6 \\
2 \theta=35.6
\end{gathered}
$$

بررسى تصوير حاصل از ميكروسكوب الكترونى مي (TEM)

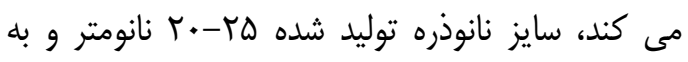

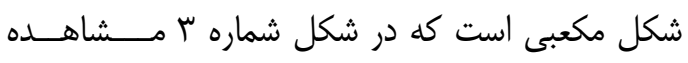
مى شود. - ا.

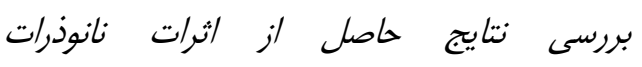

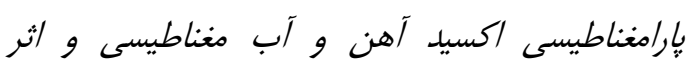

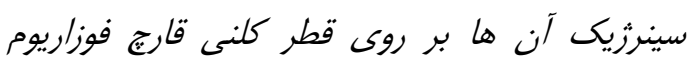

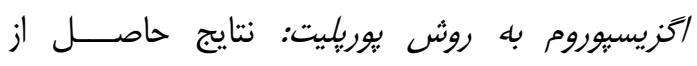
بررســـى اثر نانوذرات يارامغناطيسى اكسيد آهن با قطر

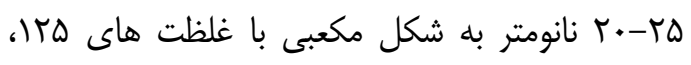

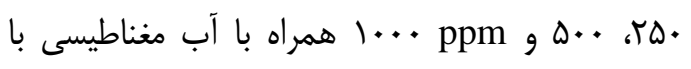

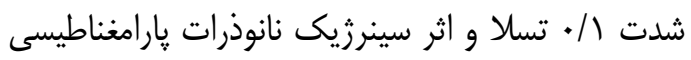

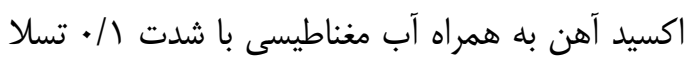

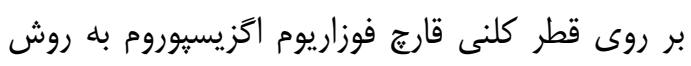

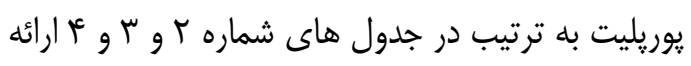

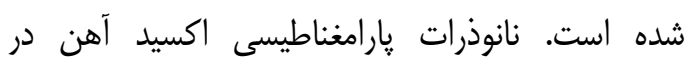

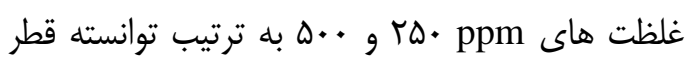
كلنى قارج را در تمام روزها كاهش دهد. كه بهترين

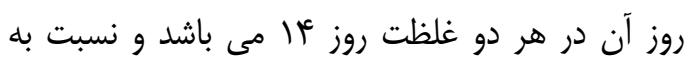

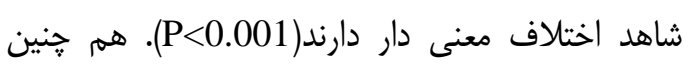

كتوكونازول ا ميلى گرم بر ميلى ليتر بوده و به وسيله

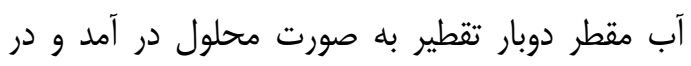

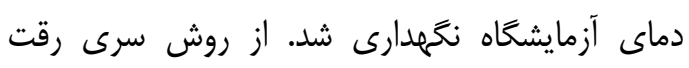

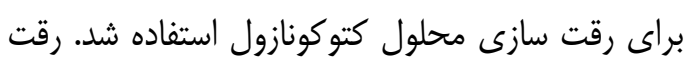
سازى داروى كتوكونازول

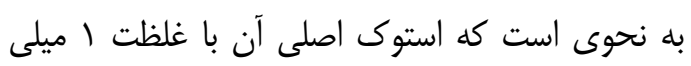
كرم برميلى ليتر بود و به اين ترتيب غلظت هاى هاى ها.

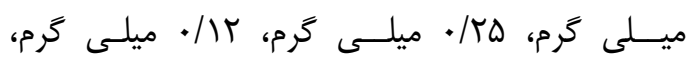
צ.

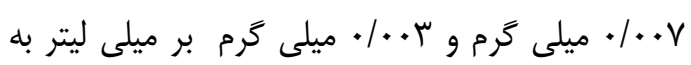
دست آمد. - (مس ميلمي

اثر داروى كتوكونازول بر روى رشد قارج فوزاريوم

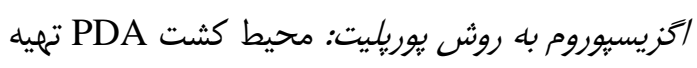

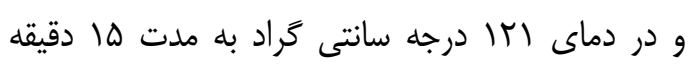

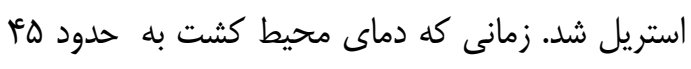

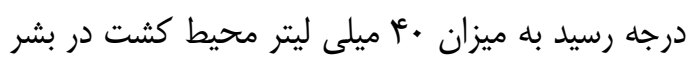

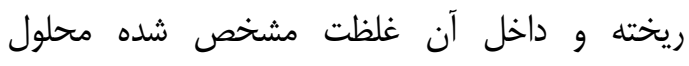
كتوكونازول اضافه شد. محيط كشت به آرامى تكان

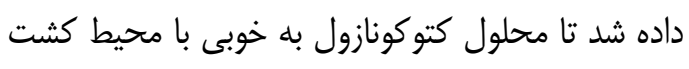
مخلوط شوند. سيس به مقدار مساوى در بّ يترى بـ به

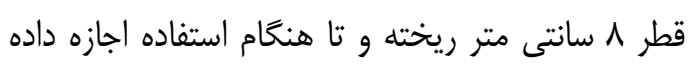

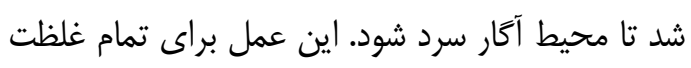

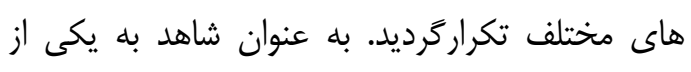

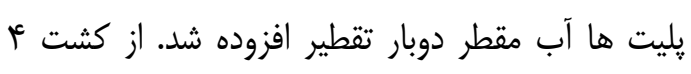

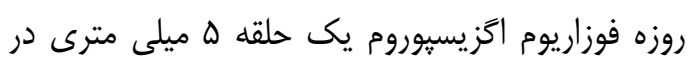

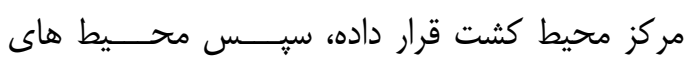

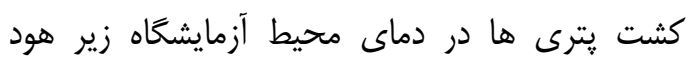

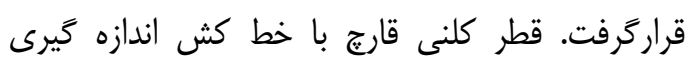

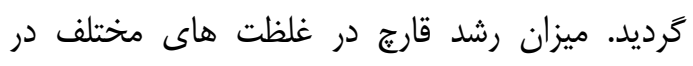

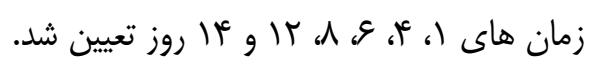

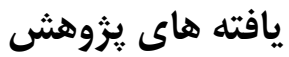

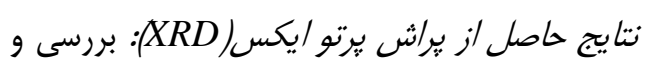

تحليل ساختار شبكه كريستالى نمونه هاى $\mathrm{Fe}_{3} \mathrm{O}_{3} \mathrm{O}_{4}$

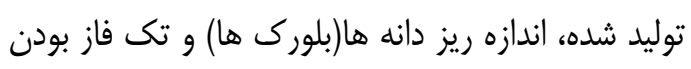
آن ها توسط طيف يراش يرتو X بر X برسى شد. با مطالعه

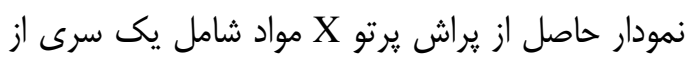

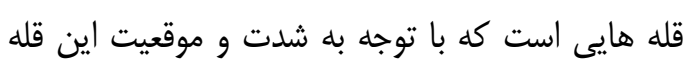
ها مى توان نمونه را با استفاده از كارت مرجع نانوذره 
نشان داد كه در تمام دوزها با افزايش غلة غإن كتوكونازول قطر كلنى قارج كاهش بيشترى ييدا كرده

$$
\text { بود. نتــــــايج }
$$

حاصل اثبات كرد كه، در يك الخوى وابسته به دوز قطر كلنى قارج كاهش يافته بود. غلظت ا ميلى ليتر در تمام روزها بيش از 19 درصد رشد قارج را مهار كرده و بيشترين اثر كشندگى روى قارج رات راش داشته

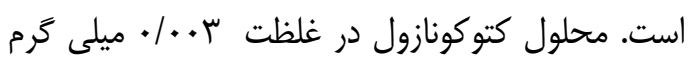
بر ميلى ليتر نسبت به غلظت هاى ديخر كمترين اثر كشندگى را روى قارج داشته است. در جدول شماره ه ه له اين نتايج نشان داده شده است.

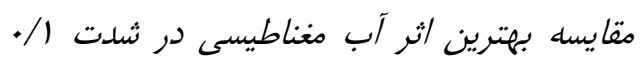
تسلا با داروى كتوكونازول بر روى قطر كلنى قارج فوزاريوم اتزيسبوروم: تحقيقات حاضر نشان داد كه به

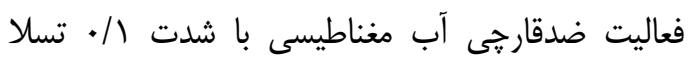
عليه قارج فوزاريوم اخزيسيوروم در مقايسه با عوامل

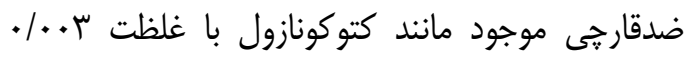

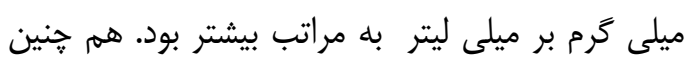
بهترين درصد مهار رشد قطر كلنى قارج فوزاريوم

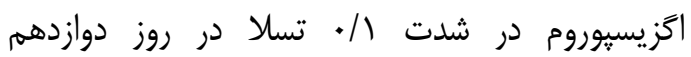

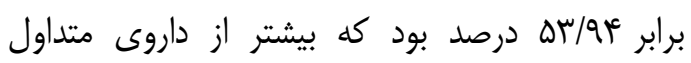
كتوكونازول ميانگين قطر كلنى قارج را مهار كرده بود. متايسه بهترين اثر نانوذرات بإرامغناطيسى اكسيد

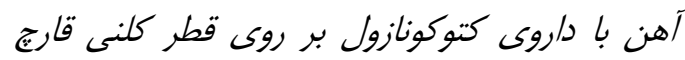

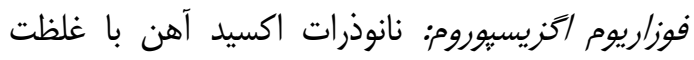

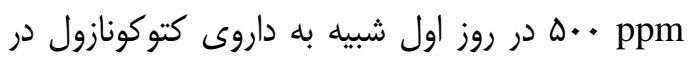

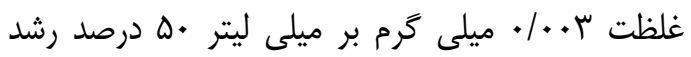
قارج را مهار كرده است.
نانوذرات اكسيد آهن با غلظت ppm • •. بهترين اثر را بر كاهش قطر كلنى قارج نسبت بد نانوذرات ديخر

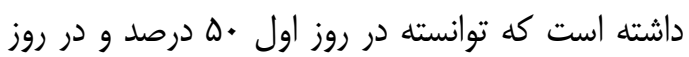
جهبارم ه/هس درصد رشد كلنى قارج را مهار كند.

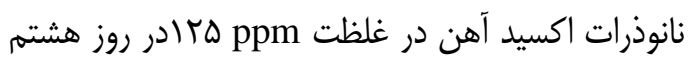
به بعد توانسته قطر كلنى قارج را ه/1 ادرصد كاهش

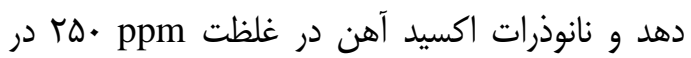

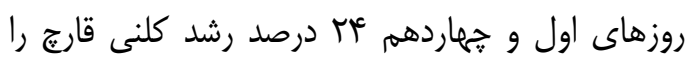
مهار كرده اند. اين نانوذرات در غلظت

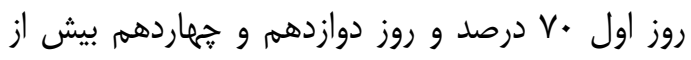
• ب درصد قطر كلنى قارج را افزايش داده اند. اين نانوذرات در غلظت بالا خاصيت ضد قارجى ندارد و به عنوان عامل تحريك كنتــــده قارج به شمار مى آيد كه در جدول شماره r نشان داده شده است. آب مغناطيسى با شدت / / • تسلا در تمام روزها قطر كلنى قارج را به ميزان زيادى كاهش داده است و اثر بيشترى نسبت به نانوذرات اكسيد آهن دارد زيرا قطر كلنى قارج را بيش از • ه درصد مهار كرده اند كه در جدول شماره س مشاهده مى كنيد. تمام غلظت هاى يلى نانوذرات اكسيد آهن وقتى با آب مغناطيسى با شدات / • • تسلا تركيب شدند داراى اثر سينرزيك در كاهش بـ قطر كلنى قارج بوده اند. اثر سينرزيك نانوذرات اكسيد

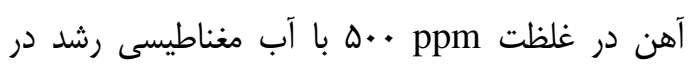

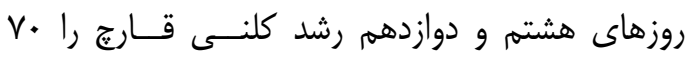
درصد مهار كرده اند كه باعث شده است خاصيت قارج كشى نانو بالاتر رود در جدول شماره ع اين نتايج نشان

داده شده است.

تفسير نتايج دارو كتوكونازول بر عليه قارج فوزاريوم اتزيسبوروم: داروى ضد قارجى كتوكونازول به عنوان كنترل مثبت عليه قارج فوزاريوم استفاده شد كه نتايج
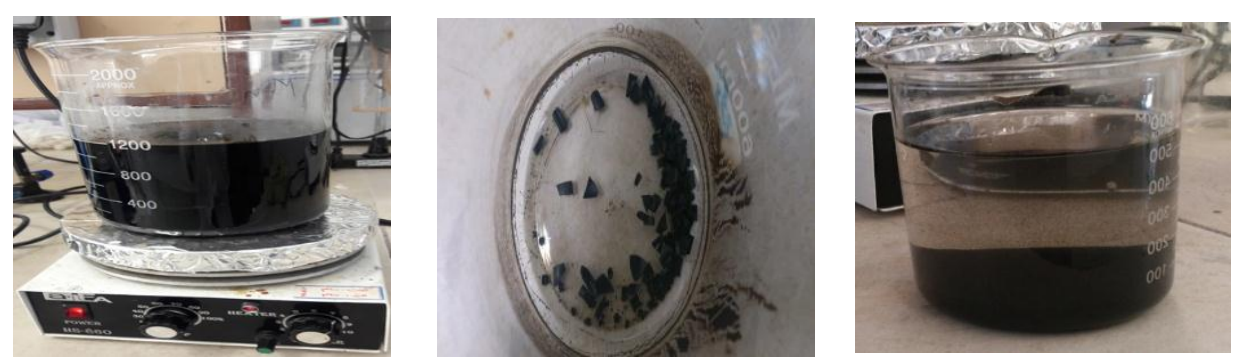

شكل شماره ا ـ سنتز نانوذرات اكسيد يارامغناطيسى اكسيد آهن 


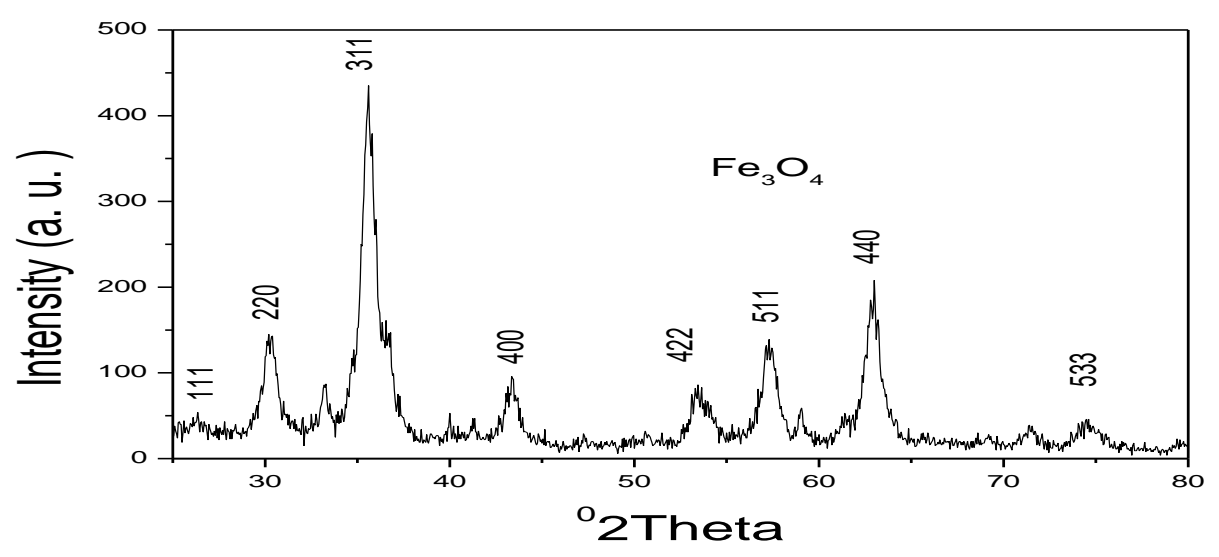

شكل شماره ז. نمودار حاصل از براش يرتو X نانو ذره اكسيدآهن(Fe
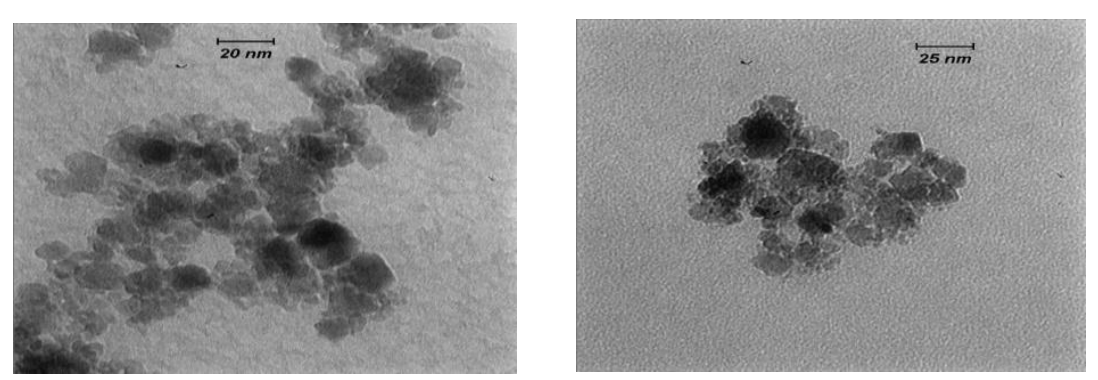

شكل شماره سّ. تصوير ميكروسكوب الكترونى نانوذرات يارامغناطيسى اكسيد آهن
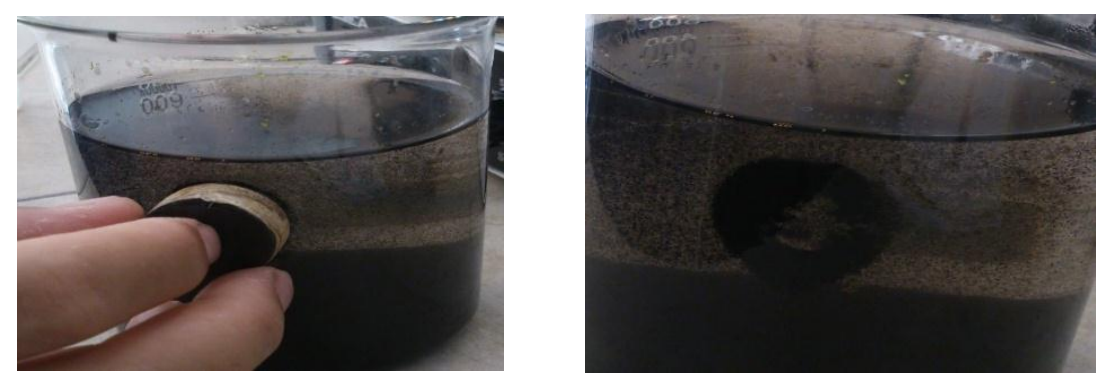

شكل شماره f. تصوير تاثير ميدان مغناطيسى روى نمونه

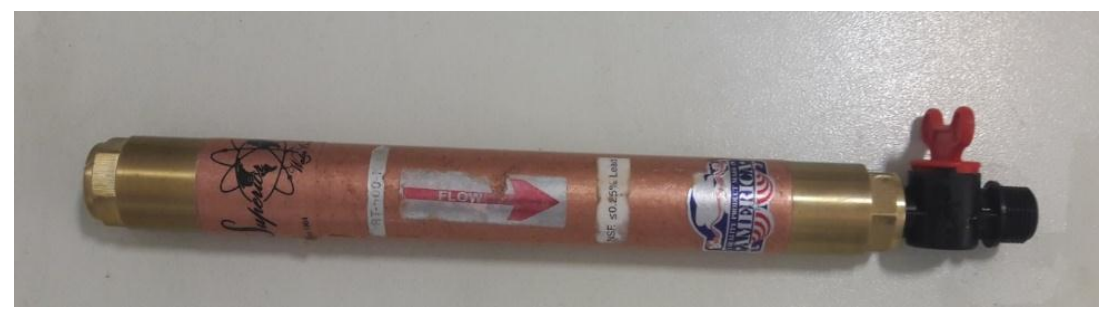

شكل شماره ه. دستَاه مغناطيسى كردن آب

جدول شماره ا. جرم مولى مواد اوليه سنتز نانوذرات يارامغناطيسى اكسيدآهن

\begin{tabular}{|c|c|c|c|c|}
\hline مواد اوليه & جرم مولى & $.1 \cdot 1$ & ضريب & كل جرم مولى بر حسب كرم \\
\hline $\mathrm{FesO}_{4}$ & $r V \Lambda$ & $r / v \Lambda$ & $1^{*}$ & $r / v \wedge$ \\
\hline $\mathrm{Fecl}_{3}$ & IST & $1 / 9 \pi$ & $r^{*}$ & $r / r F$ \\
\hline $\mathrm{NaOH}$ & r. &.$/ 4$ & $\Lambda^{*}$ & $r / T$ \\
\hline
\end{tabular}


جدول شماره ؟. تاثيرات غلظت هاى مختلف نانوذرات يارامغناطيسى اكسيد آهن بر ميانعَين قطر كلنى قارج فوزاريوم اخزيسيوروم

\begin{tabular}{|c|c|c|c|c|c|c|}
\hline \multicolumn{6}{|c|}{ ميانكين قطر كلنى قارج فوزاريوم اكزيسيوروم بر حسب سانتى متر } & \multirow{2}{*}{ 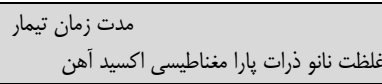 } \\
\hline روز جهاردهم & 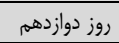 & روز هشتم & روز ششم & روز جهارم & روز اول & \\
\hline$r / \% q \pm . / \cdot 1$ & $r / \Lambda \cdot \pm \cdot / \cdot 1$ & $r / \Lambda) \pm . / \cdot 1$ & $r / \mu r \pm . / \cdot 1$ & $\tau \pm . / /$ & $1 \pm . / 1$ & شاهد \\
\hline$r / \wedge \Delta \pm . / \cdot 1$ & $r / \widetilde{\wedge \pm . / \cdot 1}$ & $r / \Delta \cdot \pm . / \cdot 1$ & $T / r Y \pm . / .1$ & $r / \cdot r \pm . / \cdot 1$ & $\cdot / \Lambda \pm \cdot / /$ & $1 T \Delta \mathrm{PPm}$ \\
\hline$\mu / \mu \cdot \pm . / \cdot 1$ & $r / r \pm \pm . / \cdot 1$ & $r / r \cdot \pm \cdot / \cdot 1$ & 1/q4.$\pm / .1$ & $1 / v 1 \pm . / \cdot 1$ & $. / V Y \pm . / .1$ & $r \Delta \cdot \mathrm{PPm}$ \\
\hline$r / \cdot 1 \pm \cdot / \cdot 1$ & $r / 9 . \pm . / \cdot 1$ & $1 / 91 \pm . / .1$ & $1 / \Delta \wedge \pm . / \cdot 1$ & $1 / / 9 \pm . / .1$ & $. / \Delta \mid \pm . / . r$ & $\Delta \cdots \mathrm{PPm}$ \\
\hline$\Delta / \wedge \uparrow \pm . / \cdot 1$ & $\Delta / 1 \backslash \pm \cdot / \cdot 1$ & $r / \mu \cdot \pm \cdot / \cdot 1$ & $r / \Delta \& \pm . / \cdot 1$ & $1 / 99 \pm . / \cdot 1$ & $1 / v 1 \pm . / \cdot 1$ & $1 \ldots \mathrm{PPm}$ \\
\hline$<\cdot / . .1$ & $<\cdot / . .1$ & $<\cdot / . .1$ & $<. / . .1$ & $<. / . .1$ & $<. / . .1$ & P \\
\hline
\end{tabular}

جدول شماره س. تاثيرات شدت آب مغناطيسى / / • تسلا بر ميانكَين قطر كلنى در قارج فوزاريوم اكزيسبوروم

\begin{tabular}{|c|c|c|c|c|c|c|}
\hline \multicolumn{6}{|c|}{ ميانكين قطر كلنى قارج فوزاريوم اكزيسيوروم بر حسب سانتى متر } & \multirow{2}{*}{ شدت آب مغناطيسى زمان تيمار } \\
\hline روز جهاردهم & 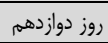 & | روز هشتم & روز ششم & روز جهارم & روز اول & \\
\hline$\varphi / \% q \pm . / . ।$ & $r / \Lambda . \pm . / .1$ & $r / \Lambda) \pm . / \cdot 1$ & $r / r Y \pm .1 .1$ & $r \pm . / 1$ & $1 \pm \cdot / 1$ & شاهد \\
\hline$r / / \varphi \pm . / . \bullet$ & $1 / v \Delta \pm . / .1$ & $\mathrm{~V} / \Delta \wedge \pm . / \cdot 1$ & $1 / 1 . \pm . / .1$ & $1 \pm \cdot / 1$ & $\cdot / \Delta \Delta \pm \cdot / \cdot \cdot$ & 11/1 • تسل \\
\hline$<\cdot|\cdot \cdot|$ & $<\cdot \mid . .1$ & $<\cdot|\cdot . \cdot|$ & $<\cdot|\cdot|$. & $<\cdot \mid . .1$ & $<\cdot|\cdot \cdot|$ & $\mathrm{P}$ \\
\hline
\end{tabular}

جدول شماره (f): تأثيرات سينر زيكى نانوذرات يارا مغناطيسى اكسيد آهن و آب مغناطيسى

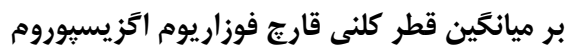

\begin{tabular}{|c|c|c|c|c|c|c|}
\hline \multicolumn{6}{|c|}{ ميانكين قطر كلنى قارج فوزاريوم اكزسيوروم بر حسب سانتى متر } & \multirow{2}{*}{ 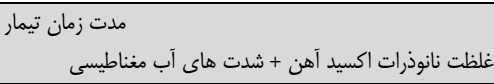 } \\
\hline 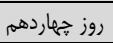 & 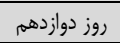 & روز هشتم & روز ششم & روز جهارم & 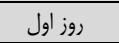 & \\
\hline$r / \% q \pm . / .1$ & $r / \Lambda \cdot \pm . / \cdot 1$ & $r / \Lambda) \pm . / \cdot 1$ & $r / \mu Y \pm . / .1$ & $r \pm \cdot / l$ & $1 \pm \cdot / 1$ & شاهد \\
\hline$r / \mu \cdot \pm . / .1$ & 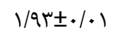 & $1 / \Delta \mid \pm \cdot / \cdot 1$ & $1 / r \cdot \pm \cdot / \cdot 1$ & $1 / 1 \cdot \pm \cdot / \cdot 1$ & $. / \Delta \wedge \pm . / .1$ & 1Tه PPm + \\
\hline $1 / v \cdot \pm \cdot / \cdot 1$ & $1 / \% \cdot \pm \cdot / \cdot 1$ & $1 / \cdot 1 \pm \cdot / \cdot 1$ & $. / 91 \pm . / .1$ & $. / V I \pm . / \cdot 1$ & $. / \Delta T \pm . / .1$ & rه. $\mathrm{PPm}+\mathrm{Y}$ \\
\hline $1 / 4 \pm . / .1$ & $1 / 11 \pm . / .1$ & $\cdot|\wedge| \pm . / \cdot 1$ & $. / \mathrm{V} \pm . / .1$ & $.199 \pm . / .1$ & $. / \Delta \pm . / \cdot 1$ & ه..PPm + \\
\hline$r / \psi \cdot \pm \cdot / \cdot 1$ & $T / 4 \cdot \pm \cdot / \cdot 1$ & $1 / v 9 \pm . / .1$ & $1 / \Delta \Delta \pm . / .1$ & $1 / 4 \cdot \pm \cdot / \cdot 1$ & $.191 \pm . / .1$ & 1...PPPm + \\
\hline$<\cdot / . .1$ & $<\cdot / . .1$ & $<\cdot / . .1$ & $<\cdot / . .1$ & $<\cdot / . .1$ & $<\cdot / . .1$ & $\mathrm{P}$ \\
\hline
\end{tabular}

جدول شماره ه. مقايسه اثر غلظت هاى مختلف داروى كتوكنازول بر روى قطر ميانكين كلنى قارج فوزاريوم اتزبسبوروم

\begin{tabular}{|c|c|c|c|c|c|c|}
\hline روز جهاردهم & روز دوازدهم & روز هشتم & روز ششم & روز ههارم & روز اول & 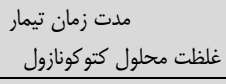 \\
\hline$\varphi / \% q \pm \cdot / \cdot 1$ & $r / \Lambda \cdot \pm \cdot / \cdot 1$ & $r / \Lambda) \pm \cdot / \cdot 1$ & $r / r Y \pm . / \cdot 1$ & $r \pm . / 1$ & $1 \pm . / 1$ & شاهد \\
\hline 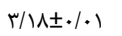 & $r / 9 \mid \pm . / .1$ & 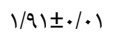 & $1 / 4 \varphi \pm . / .1$ & $1 / \% \Delta \pm . / .1$ & $\cdot / \Delta \pm \cdot / 1$ & . \\
\hline$r / \Delta \cdot \pm \cdot / \cdot 1$ & $r / \mu \backslash \pm . / .1$ & $1 / / 9 \pm . / .1$ & $1 / T E \pm .1 \cdot 1$ & $1 / 1 \Lambda \pm . / .1$ & $. / \Delta \pm . / .1$ & $. / . \vee \mathrm{mg} / \mathrm{ml}$ \\
\hline $1 / v^{e} \pm . / .1$ & $1 / \Delta \Delta \pm \cdot / \cdot 1$ & $1 / / 9 \pm . / .1$ & $1 / / 9 \pm . / \cdot 1$ & $1 / \cdot \vee \pm . / \cdot 1$ & $\cdot / \Delta \pm \cdot / \cdot \cdot \Delta$ & $. / .1 \mathrm{mg} / \mathrm{ml}$ \\
\hline $1 / \leftarrow \wedge \pm . / .1$ & $1 / \mu 1 \pm .1 \cdot 1$ & $1 / / \Lambda \pm . / .1$ & $1 / 11 \pm \cdot / \cdot 1$ & $. / N^{e} \pm . / .1$ & $\cdot / \Delta \pm . / \cdot 11$ & $. / . r \mathrm{mg} / \mathrm{ml}$ \\
\hline $1 / \% \Delta \pm . / \cdot 1$ & $1 / r \cdot \pm \cdot / \cdot 1$ & $1 / 1 r \pm . / .1$ & $\mid \pm . / 1$ & $\cdot / \mathrm{N} \pm \cdot / /$ & $. / \propto q \pm . / . \cdot \Delta$ & $.1 .9 \mathrm{mg} / \mathrm{ml}$ \\
\hline $1 / \Upsilon \Lambda \pm . / .1$ & $1 / 1 \cdot \pm \cdot / \cdot 1$ & $1 / \cdot 1 \pm \cdot / \cdot 1$ & $. / 9 \pm \cdot / 1$ & $\cdot \mid q 4 \pm . / \cdot 1$ & $\cdot / \Delta \pm \cdot / \cdot 1$ & $. / \mathrm{rmg} / \mathrm{ml}$ \\
\hline $1 / .9 \pm . / .1$ & $. / 99 \pm . / .1$ & $\cdot / \wedge \pm \cdot / 1$ & $\cdot / v \pm \cdot / 1$ & $\cdot / \Delta \wedge \pm \cdot / \cdot 1$ & $. / \Delta \pm . / .1$ & $\cdot / r \Delta \mathrm{mg} / \mathrm{ml}$ \\
\hline$\cdot / \Lambda \Delta \pm . / \cdot 1$ & $\cdot / v \pm \cdot / 1$ & $.199 \pm .1 .1$ & $.19 \pm . / 1$ & $\cdot / \Delta \pm . / . \cdot \Delta$ & $. / \Delta \pm . / . r$ & $. / \Delta \mathrm{mg} / \mathrm{ml}$ \\
\hline$\cdot / v \Delta \pm . / .1$ & $\cdot \mid \varepsilon \Delta \pm \cdot / \cdot 1$ & $. / \Delta T \pm . / . T$ & $\cdot /<q \pm * / \cdots \Delta$ & $\cdot / \Delta \pm \cdot / \cdot 11$ & $\cdot / \Delta \pm . / \cdot \Delta \Delta$ & $1 \mathrm{mg} / \mathrm{ml}$ \\
\hline$<\cdot / . .1$ & $<\cdot / . .1$ & $<\cdot \mid \cdot .1$ & $<\cdot \mid \cdot . \cdot 1$ & $<\cdot \mid \cdot .1$ & $<\cdot \mid \cdot \cdot 1$ & $P$ \\
\hline
\end{tabular}

آن ها نشان داد كه نانوذرات نقره در ابعاد هr-+r نانومتر بيشترين فعاليت ضد باكتريايى را بين ساير نانوذرات ساختخى دارا مى باشند. هر يك از نانوذرات نقره و نانوذرات تيتانيوم اكسايد به تنهايى فعاليت ضدقارجى كمى داشتند اما زمانى كه در طى دوره سنتز با يكديخر تركيب شدند، فعاليت ضدقارجى آن هاني

\section{بحث و نتيجه تَيرى}

مارتينز-گوتيريز و همكاران در سال • • + ب با سنتز ها نوع از نانوذرات نقره، نانوذرات تيتانيوم اكسايد و هون

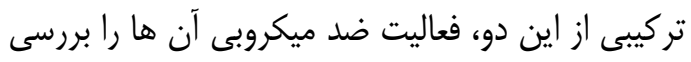

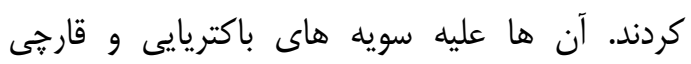
فرصت طلب و ياتوزن را مورد بررسى قرار دادند. نتايج 
بود را بررسى كردند نتايج آن ها نشان داد نانوذرات

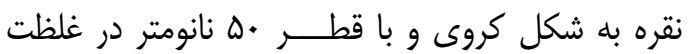
حل م r ppm حدود •ه درصد كاهش داده اند. در زمان كمتر نانوذرات نقره كاهش جشمخيرى در رشد ريسه هاى إند داين قارج داشته است، بنا بر اين نانوذرات نقره علاوه بر خاصيت

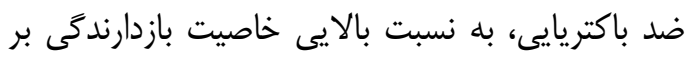
عليه عامل بيمارى گياهى قارج فوزاريوم دارند. نتايج حاصل از تحقيق حاضر نشان داد كه اثر ضدقارئ بارئ نانوذرات آهن كمتر از نانوذرات نقره است. احتمات الاً علت

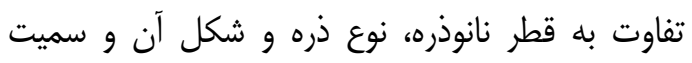

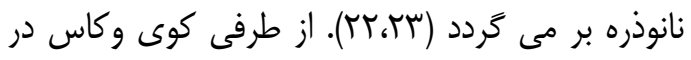

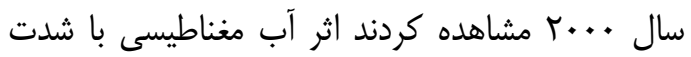
1/· تسلا در حوضجه يرورش ماهى ها اكسيثن محلول را به ميزان قابل توجهى افزايش مي دهى دهد. زيرا

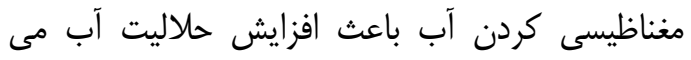

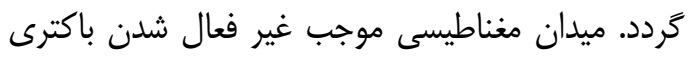

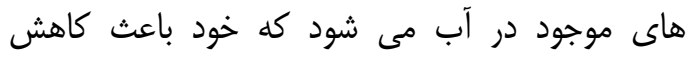

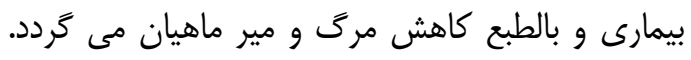

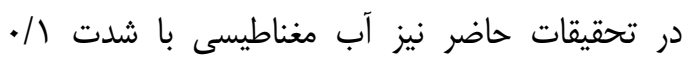

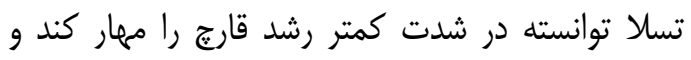

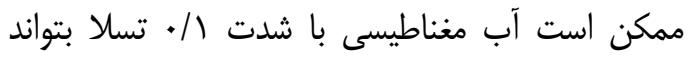

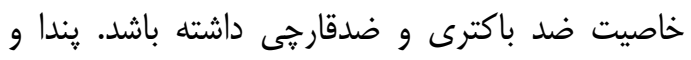

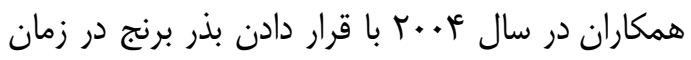

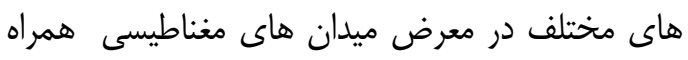

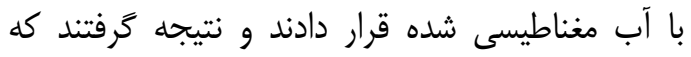

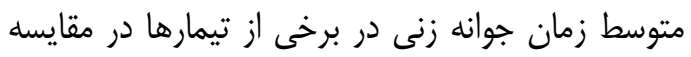

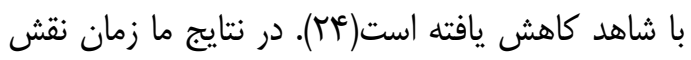

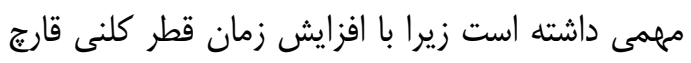

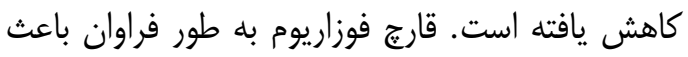

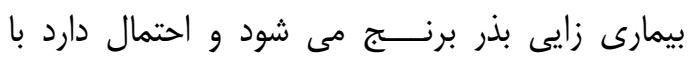
استفاده از آب مغناطيسى بتوان بيمارى زايى بذر بـ برنج

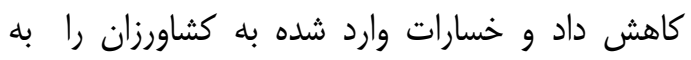
حداقل رساند. نتايج حاصل از تحقيق حاضر نشان مى دهد كه

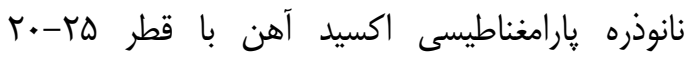

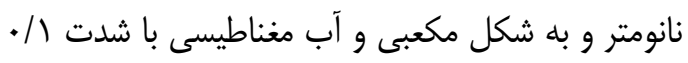

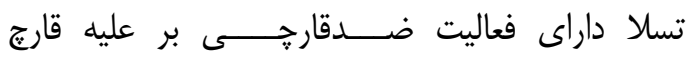

افزايش يافت(1)). هم קنين ميشراو همكاران در سال

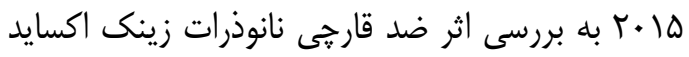

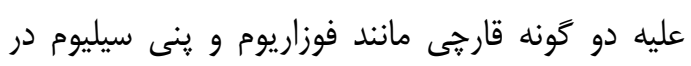

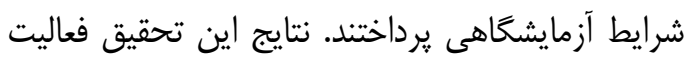

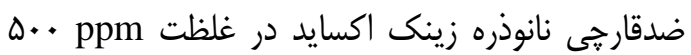
را نشان داد(9). در تحقيق حاضر نيز اثر ضدقارجى

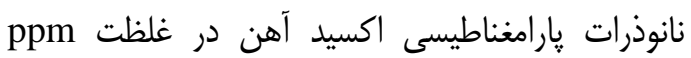

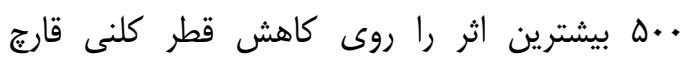

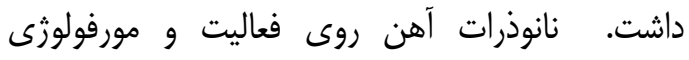
باكترى هايى نظير اشرشياكلاى، سودوموناس و غيره

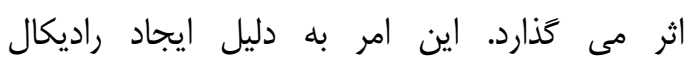

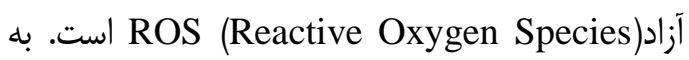
طور مثال سويراكسيد و راديكال هاى هيدروكسيل و يراكسيد هيدروزن و يكى واحد اكسيثن باعث آسيب به هيه

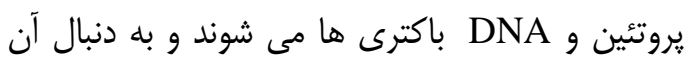

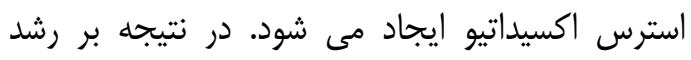

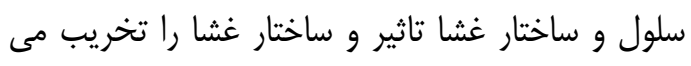

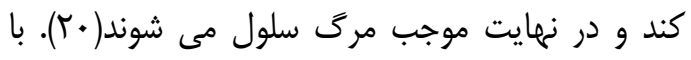

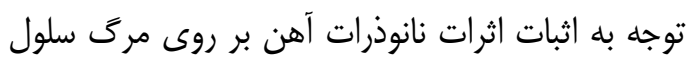

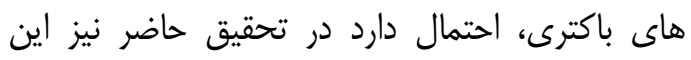

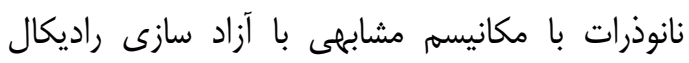

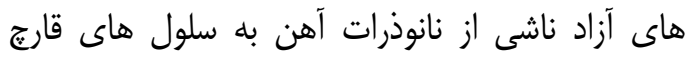

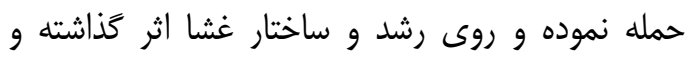

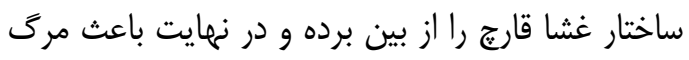

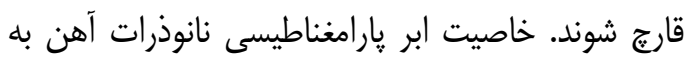
عنوان يك خاصيت مهم در كاربردهاى يزشكى مد نظر

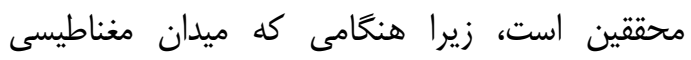

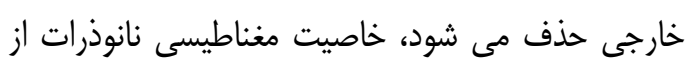

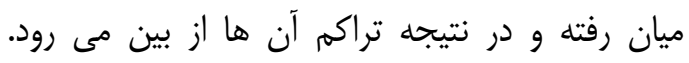

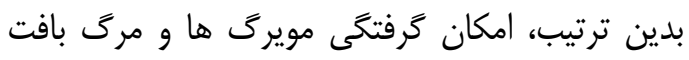

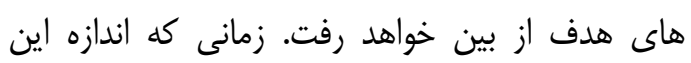

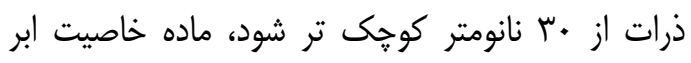

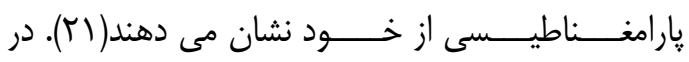

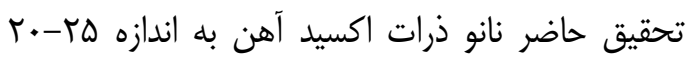

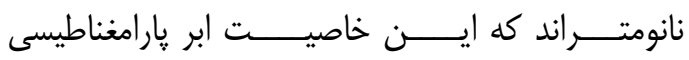

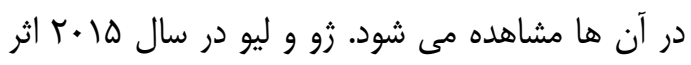

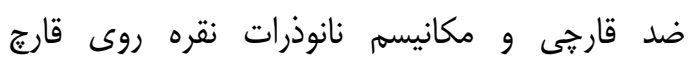

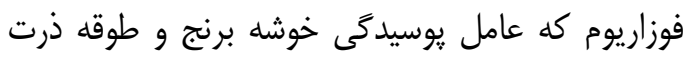




$$
\begin{aligned}
& \text { بررسى ايمن بودن نانوذرات يارا مغناطيسى اكسيد آهن }
\end{aligned}
$$

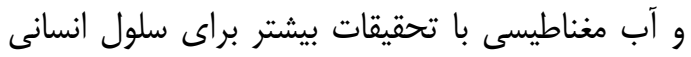

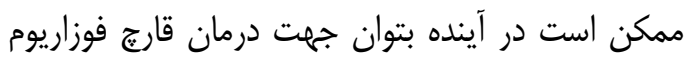

$$
\begin{aligned}
& \text { اكزيسبوروم از آن استفاده كرد. }
\end{aligned}
$$

\section{References}

1. Elmer WH, Covert SF, Donnell K. Investigation of an outbreak of Fusarium foot and fruit rot of pumpkin within the United States. Plant Dis 2007; 91: 1142-6. doi:10.1094/PDIS-91-1142.

2. Maran PN, Magan CV, Ajzquez A, Gonzajlez MT, Jaacn S. Differential effect of environmental conditions on the growth and regulation of the fumonisin biosynthetic gene FUM1 in the maize pathogens and fumonisin producers Fusarium verticillioides and Fusarium proliferatum. FEMS Microbiol Ecol 2010; 73: 303-11. doi:10.1111/j.1574-6941.

3. Kim KJ, Sung WS, Suh BK. Antifungal activity and mode of action of silver nanoparticles on Candida albicans. Biometals 2009; 22:235-42. doi:10.1007/S10534-008-91592-2.

4. Sriram MI, Barath S, Kanth M, Kalishwaralal K, Gurunathan S. Antitumor activity of silver nanoparticles in Dalton's lymphoma ascites tumor model. Int J Nanomed 2010; 5: 620-753. doi:102147/IJN.S11727.

5. Wildfeuer AH, Seidl I, Paule A. Haberreiter. In vitro evaluation of voriconazole against clinical isolates of yeasts moulds and dermatophytes in comparison with itraconazole, ketoconazole amphotericin B and griseofulvin. Mycoses 1998; 41: 309-19. doi:10.111/J.1439-0507.

6. Schultz S, Smith DR, Mock JJ, Schultz DA. Single target molecule detection with nonbleachingmulticolor optical immunolabels. Proce National Acad Sci USA 2000;97:996-1001. doi:10.1073/pnas.97.30996.

7. Zhao ZL, Bian ZY, Chen LX, He XW, Wang YF. Synthesis and surface modifications of iron oxide magnetic nanoparticles and applications on separation and analysis. Prog Chem 2006; 18:1288-97. 8. Amedea B, Seabra N, Nelson D. Nanotoxicology of metal oxid nanoparticles

$$
\begin{aligned}
& \text { فوزاريوم اخزيسيوروم باشد. با در نظر گرفتن اين نكته } \\
& \text { كه تركيبات رايج امروزى كه براى درمان انواع عفونت }
\end{aligned}
$$

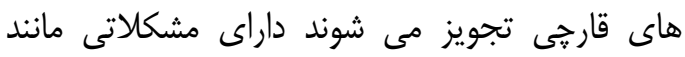

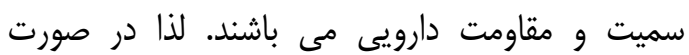

a review. J Metals 2015; 5: 934-75. doi:10.3390/met5020934.

9. Zhu X, Radovic AF, Wu J, Langer R, Shi J. Nanomedicine in the management of microbial infection overview and perspectives. Nanotecnology 2014; 9: 47898. doi:10.1016/j.nant.d.06.003.

10. Kafayati ME, Raheb J, Torabi Angiy M, Alizadeh S, Bardania $H$. Effect of magnetic nanaoparticles of iron oxide on bacterial growth activity of Pseudomonas Sulfur. Iran J Biotechnol Kosar 2013; 1: 4146.

11. Maheshwari BL, Grewal HS. Magnetic treatment of irrigation water its effects on vegetable crop yield and water productivity. Agr Water Manage 2009; 1:1229-36. doi:10.1016j.agwat.03.16.

12. Abdulqados AMS, Hozayn M. Response of growth yield yield components and some chemical constituents of flax for irrigation with magnetized and tap water. World Appl Sci J 2010; 8: 630-4.

13. Coey JMD, Cass S. Magnetic water treatment. J Magnet Mate2000;209:71-4. . doi:10.1016/s0304-88539900648-4.:

14. Amire GhR, Yousefi $\mathrm{MH}$, Aboulhassani MR, Kesgavarz MH, Fatahian S, Alahi M. Redar absor otion of Nio.zn. $3 \mathrm{fe}_{3} \mathrm{O}_{4}$ nanoparticles digest. J Nanomat Biostru2010; 5:1025-31.

15. Gilani A, Kermanshahi H, Golian A, Gholizadeh M, Mohammadpour A. Evaluation of Magnetized Drinking Water on Carcass Yield and Performance of Broiler Chickens. Iranian J Anim Sci Res 2016;8: 86-95.

16. Fliniaux F, François Mesnard F, Sophie Raynaud S, Fliniaux O. Santhetis iron oxide materials method. J Exp Botany 2004; 55: 1051-3.

17. Iranbakhsh A, Ebadi M, Bayat M. The Inhibitory effects of plant methanolic extract of daturastramoniumL. and Leaf explant callus against bacteria and fungi. Global Vet2010; 4:149-55. 
18. Martinez F, Olive PL, Banuelos A, Orrantia E, Nino N, Morales E. Synthesis characterization and evaluation of antimicrobial and cytotoxic effect of silver and titanium nanoparticles. Nanomed Nanotechnol Biol Med 2010; 6: 681-688. doi:10.1016/j.nano.20001.

19. Ramy S, Yehia A, Osma FA. Invitro study of the antifungal efficacy of zinc oxide nanoparticles against Fusarium oxysporum and Penicilium expansum methods of nanoparticles for medical and commercial applications. Biotechnol Impl2013;7:1917-23. doi:10.5897/AJMR.5668.

20. Bharde AA, Parikh RY, Baidakova $M$, Jouen S, Hannoyer B, Enoki $T$. Bacteria-mediated precursor-dependent biosynthesis of superparamagnetic iron oxide and iron sulfide nanoparticles. Langmuir 2008; 24: 5787-5794. doi:10.1021/a704019p.
21. Varadan VK, Chen L, Xie J. Nanomedicine: design and applications of magnetic nanomaterials nanosensors and nanosystems.Wiley Am J Ed 2008; 1: 42150.

22. Zhu YY, Liao LM. Applications of nanoparticles for anticancer drug delivery a review J Nanosci Nanotechnol 2008; 5 : 1441-50. doi:10.1158/1078-0432.

23. Sunitha A, Abdeen RS, Sweetly G, Sornalekshmi S, Arsula R. Evaluation of antimicrobial activity of biosynthesized iron and silver nanoparticles using the fungi fusarium oxysporum and actinomycetes sp. on human pathogen. Nanobiomed Eng 2013;5:39-45. doi:10.5101/neb.v5il.

24. Panda RK, Behera SK, Kashyap PS. Effective management of irrigation water for maize under stressed conditions. Agri Water Manage 2004; 66: 181-203. doi:10.1016/j.awat.12.001. 


\title{
Comparison of paramagnetic iron oxide nanoparticles and magnetic water on the growth of Fusarium oxysporum
}

\author{
Babashahi $P^{l}$, Naghsh $N^{2 *}$, Madani $M^{l}$
}

(Received: February 6, 2017

Accepted: April 4, 2017)

\begin{abstract}
Introduction: The resistance of opportunistic fungal strains has been on a growing trend in the recent years. The toxicity of antimicrobial drugs, development of fungal resistance, and incidence of drug interactions account for the consideration of new drug combinations against fungi. Regarding this, the present study was conducted to perform an in vitro investigation on the effect of paramagnetic iron oxide nanoparticles and magnetic water on Fusarium oxysporum.
\end{abstract}

Materials and Methods: The synthesis of paramagnetic iron oxide nanoparticles was conducted in Islamic Azad University, Falavarjan Branch, Falavarjan, Iran, using the co-precipitation method. The antifungal effects of paramagnetic iron oxide nanoparticles and the impact of magnetic water with an intensity of 0.1 Tesla on Fusarium oxysporum were investigated using pur plate technique. Accordingly, the percentage of Fusarium oxysporum growth inhibition was determined.

Findings: The results of X-ray diffraction and electron microscopy showed that iron oxide nanoparticles had a diameter of 20-25 $\mathrm{nm}$ with a cubic shape. Based on the results of pur plate technique, 0.1 Tesla magnetic water reduced the diameter of Fusarium oxysporum colonies by more than $49.64 \%$ on all days. In addition, the iron oxide nanoparticles at a concentration of $500 \mathrm{ppm}$ inhibited the diameter of the fungal colony by more than $30 \%$ on all days. Furthermore, the combination of iron oxide nanoparticles at a concentration of $500 \mathrm{ppm}$ with 0.1 Tesla magnetic water inhibited the growth of fungal colonies by more than $50 \%$. Therefore, the combined method exerted the greatest synergistic impact on reducing the diameter of the fungal colony. Similar to ketoconazole (concentration of 0.003 $\mathrm{mg} / \mathrm{ml}$ ), on the first day, iron oxide nanoparticles with a concentration of 500 ppm inhibited fungal growth. However, on the twelfth day, 0.1 Tesla magnetic water had a better performance, compared to ketoconazole as a conventional antifungal drug.

Conclusion: As the findings indicated, paramagnetic iron oxide nanoparticles with a diameter of 20-25 $\mathrm{nm}$ alone and in combination with 0.1 Tesla magnetic water had magnetic antifungal activity against Fusarium oxysporum.

Keywords: Paramagnetic iron oxide nanoparticles, Magnetic water, Fusarium oxysporum, Antifungal effect

1. Department of Microbiology, Islamic Azad University, Falavarjan Branch, Isfahan, Iran

2 Department of Biology, Islamic Azad University, Falavarjan Branch, Isfahan, Iran

Corresponding author: Email: n_naghsh@yahoo.com

Scientific Journal of Ilam University of Medical Sciences 